Article

\title{
Forecasting Monthly Prices of Japanese Logs
}

\author{
Tetsuya Michinaka *, Hirofumi Kuboyama, Kazuya Tamura, Hiroyasu Oka and \\ Nobuyuki Yamamoto
}

Department of Forest Policy and Economics, Forestry and Forest Products Research Institute (FFPRI), Matsunosato, Tsukuba, Ibaraki 305-8687, Japan; kuboyama@affrc.go.jp (H.K.); nickteio@ffpri.affrc.go.jp (K.T.); oka@affrc.go.jp (H.O.); n.yamamoto@affrc.go.jp (N.Y.)

* Correspondence: michinaka.t@affrc.go.jp; Tel.: +81-29-829-8321; Fax: +81-29-873-3799

Received: 8 January 2016; Accepted: 18 April 2016; Published: 26 April 2016

\begin{abstract}
Forecasts of prices can help industries in their risk management. This is especially true for Japanese logs, which experience sharp fluctuations in price. In this research, the authors used an exponential smoothing method (ETS) and autoregressive integrated moving average (ARIMA) models to forecast the monthly prices of domestic logs of three of the most important species in Japan: sugi (Japanese cedar, Cryptomeria japonica D. Don), hinoki (Japanese cypress, Chamaecyparis obtusa (Sieb. et Zucc.) Endl.), and karamatsu (Japanese larch, Larix kaempferi (Lamb.) Carr.). For the 12-month forecasting periods, forecasting intervals of $80 \%$ and $95 \%$ were given. By measuring the accuracy of forecasts of 12- and 6-month forecasting periods, it was found that ARIMA gave better results than did the ETS in the majority of cases. However, the combined method of averaging ETS and ARIMA forecasts gave the best results for hinoki in several cases.
\end{abstract}

Keywords: log prices; forecasting; forecasting interval; exponential smoothing; ARIMA

\section{Introduction}

Fluctuations and low levels of log prices in Japan are a challenge for forest owners in managing forests. As a result, processing mills experience difficulties in ensuring a stable supply of suitable logs. Additionally, the mismatch between the supply of and demand for logs leads to sharp fluctuations in $\log$ prices, such as that observed in the former half of 2012 [1]. In other words, log prices not only affect the profitability of forest owners, logging companies and sawmills, but might also affect the daily operations in sawmills. Therefore, having information on future log prices can be useful for the aforementioned parties in their risk management. For example, information about potential price fluctuations will perhaps allow suppliers and users of logs to adjust their supply and demand. When private suppliers of logs feel it is difficult to adjust their supplies due to small size of their operations and the need to cover daily maintenance costs, state-owned forests managers might play an important role by adjusting their supplies of logs. However, forecasts of log prices in Japan have rarely been provided, though analyses on fluctuations in the prices of Japanese logs started long ago.

The impacts of various supply and demand factors on log prices have been studied and the existence of seasonal fluctuations confirmed as early as in the late 1920s [2]. Log prices are found to be at their lowest in June and July and to reach their peak in October and November due to the seasonal nature of construction (spring and autumn were peak times), but, in 1910-1920's, seasonal fluctuations have become less pronounced, about $1 \%$ of the annual average prices [2]. Recently, a monthly seasonal price index for logs of different origins (e.g., Mainland Japan, North America, Hokkaido, South Asia, and Taiwan) in Tokyo and Osaka markets has been calculated [3], but, in response to this research, it was noted that the seasonal increase in autumn is rather limited and should not be expected, because the general commodity market is thought to be more important [4]. Since the 1960s, not only the seasonal fluctuations, but the trend movement in log prices with the changes in supply and demand 
has also been analyzed [5-8]. The cyclical fluctuations and their relationship with the diffusion index, apart from demand and supply, have also attracted the attention of researchers [9]. The number of months from one valley to the next valley were calculated to show the cycles of timber prices [9]. In the 1980s, a decomposition method, which was developed by Economic Planning Agency, Japan, originating from the Census Method II approach (US Census Bureau), was used in analyzing the trend, cycle, and seasonal movements for log price time series along with their influencing factors [10]. In the 2000s, the X-12-ARIMA approach, developed by U.S. Census Bureau and mainly used for seasonal adjustment, was adopted to decompose the price time series into trend components, seasonal components, and irregular components for nine forest products in two private auction markets in the Kyushu region [11]. A recent study in the field analyzed the relationship between monthly prices and $\log$ inventory in sawmills and stated that pest damage is the reason for low prices from June to August [12]. Although the aforementioned research studies paid attention to price fluctuations, few forecasts could be found among them. In the 1970s, a two-step foresting approach was once adopted in which the price time series was decomposed into the following components: secular trend variation, which is determined by stock supply; seasonal variation, which is caused by the seasonal change in activities in construction; cyclical fluctuation, which is largely caused by business cycle; and random variation, which is fitted into an AR mode. These components were then combined together using the models established in the above stages for forecasting. As for the forecasting period, two years of monthly forecasts were provided, as were the lower and upper limits of forecasts at the $70 \%$ level, but the methods used to calculate these lower and upper limits were not explained [7]. Moving average (MA), autoregressive moving average (ARMA), and seasonal autoregressive integrated moving average (ARIMA) models were once used for fitting price time series of some sawnwood and logs, and it was concluded that the most reasonable forecast results were obtained by using the seasonal ARIMA [11], even though only a simple form of the ARIMA model was considered.

Short-term forecasting of a time series is possible because each time series has its own pattern of movements. To do a forecast well, a good grasp of the situation is important, and forecasters need to make subjective judgments at times. Therefore, statistical forecasting can be described as "the blend of art and science" [13], and the objective of time series forecasting is "to discover the pattern in the historical data series and extrapolate that pattern into the future" [14]. More complicated models are not considered in this research because model simplicity is preferred, though exponential smoothing method (ETS) and ARIMA have evolved into complicated forms already.

ETS and ARIMA have made great progress since the 1990s [14,15]. The free software $R[16]$ and the package forecast [17] make specifying parameters and comparing models much easier. ETS's model framework has made progress by introducing the state space model as well as other developments, such as stochastic models, likelihood calculation, prediction intervals, and procedures for model selection [15].

In this research, by applying the latest model specification and selection instruments and the algorithm in software $R$ ( $R$ Core Team, Vienna, Austria), we analyze the movements in prices of domestic Japanese sawlogs-sugi, hinoki, and karamatsu. We then forecast log prices 12 months ahead by using ETS and ARIMA. In addition to point forecasts, we give forecast intervals at the $80 \%$ and $95 \%$ levels. Additionally, we apply valuations for forecast accuracy to forecast results given by ETS and ARIMA and concluded that, in most cases, ARIMA obtains better forecasts than ETS does.

\section{Materials and Methods}

\subsection{Study Objects and Their Data}

Forests in Japan cover about $67 \%$ of the total area and, due to aggressive planting since 1950 s, the area of planted forests in Japan extends to over 10 million ha, which is $40 \%$ of the total forest area. Due to the low level of harvest volume compared to the growth level, the total forest stock keeps increasing, and the average growing stock per hectare comes to over $190 \mathrm{~m}^{3}$ [18]. In Japan, most forest 
owners and sawmills are small in scale. It is difficult for small owners to provide a steady supply of logs, and it is difficult for small mills to produce kiln-dried sawnwood to compete against foreign sawnwood. Increasing costs, which are partly driven by increasing wages, are another factor for the low competitiveness of domestic logs and sawnwood. The production of logs declined to 15 million $\mathrm{m}^{3}$ by 2002 from 51 million $\mathrm{m}^{3}$ in 1967, when Japan opened the door to foreign timber products. After the efforts of the Japanese government and wood industry to promote domestic wood, the self-sufficiency rate of wood recovered from its lowest point of $18.2 \%$ in 2002 to $31.2 \%$ in 2014 [19].

The top three species for log production in Japan-sugi, hinoki, and karamatsu-are mainly harvested from the planted forests. In 2014, the production volumes for these three species are 11.19 million $\mathrm{m}^{3}$ (56\% of the total $\log$ production), 2.40 million $\mathrm{m}^{3}(12 \%)$, and 2.37 million $\mathrm{m}^{3}(12 \%)$, respectively [20]. The main prefectures for sugi production are Miyazaki, Akita, Oita, and Kumamoto; the top producers for hinoki are Okayama, Kochi, Ehime, and Kumamoto; and for karamatsu, they are Hokkaido, Iwate, and Nagano (see Figure 1). Sugi and hinoki sawnwood are mainly used in housing construction, and karamatsu sawnwood is mainly used as packaging materials for the storage and transportation of commodities.

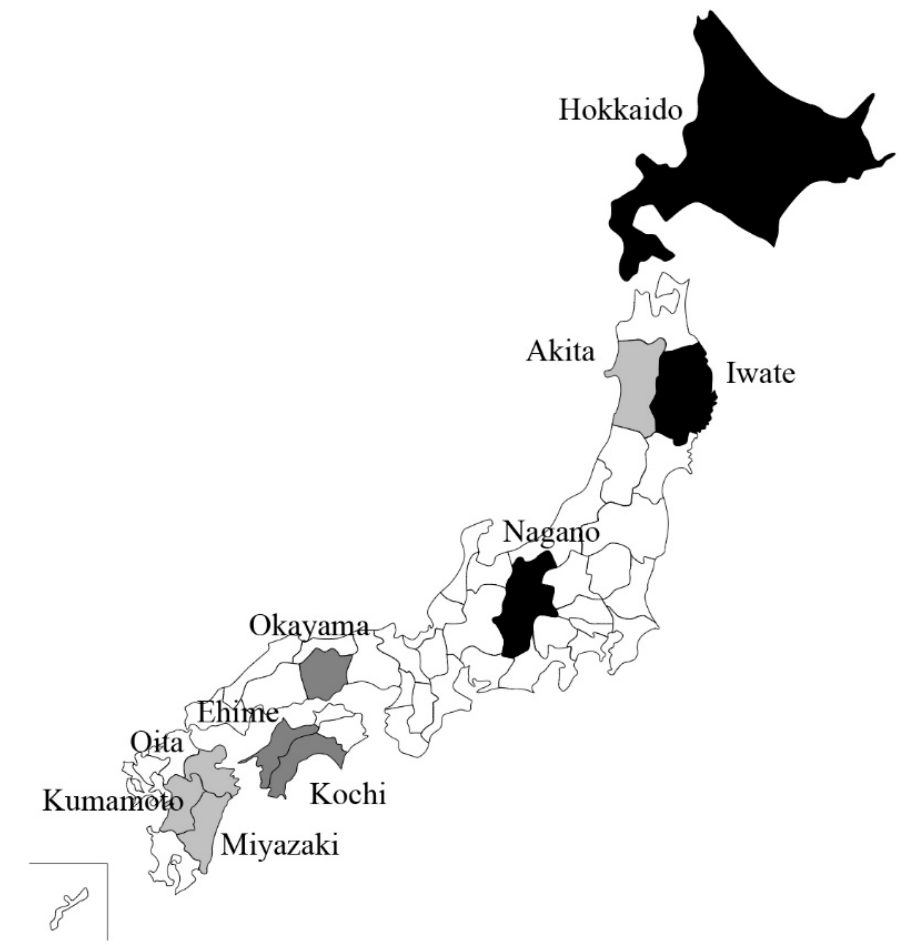

Figure 1. Top production regions of sugi, hinoki, and karamatsu logs. The darkest color shows the production regions for karamatsu; the brightest color for production regions of sugi; while others for hinoki.

Logs of different diameters and lengths might have different usages, which translates into different prices. In this research, we analyze sugi, hinoki, and karamatsu logs in their most common diameters and lengths for sawnwood processing. For sugi and hinoki, the diameter is $14-22 \mathrm{~cm}$, for karamatsu, it is $14-28 \mathrm{~cm}$; the length considered for the logs of the three species is $3.65-4.00 \mathrm{~m}$ [20]. The prices are monthly volume-weighted average prices for all grades of logs that are used in processing sawnwood under the above-stated diameters and lengths. Our objective is to provide short-term forecasts; thus, considering the data availability, we think that monthly data are suitable.

Given that 2002 was the year when domestic log production decreased to its lowest point since 1960 and subsequently increased, monthly data from January 2002 to September 2015 are used in this research. The current value for monthly prices for logs was sourced from the Ministry of Agriculture, 
Forestry and Fisheries (MAFF) [20]. Japan experienced deflation after the mid-1990s. However, the situation has changed since 2012, when Abenomics policies began to be implemented. Considering the possible impacts of general price level changes on the movements in log prices, we introduced the Corporate Goods Price Index (CGP) to adjust the monthly log prices to a constant value as that in 2010.

\subsection{Methods}

In the short-term forecasting of monthly prices of logs, we applied ETS and ARIMA, two typical forecasting approaches, though many methods have been proposed and applied in the field [14,21-27], and there are "as many forecasting methods as there are forecasters" [28]. Further, the naïve (or seasonal naïve, shortened as Snaïve) method was also introduced as a reference for measuring the accuracy of forecasting. Because we only used the time series data of monthly log prices and no other variables were included (e.g., housing starts on the demand side, forest resources on the supply side), our research is a univariate time series analysis. Root mean square error (RMSE), mean absolute error (MAE) and mean absolute percentage error (MAPE) are calculated in measuring the accuracy of forecasting results.

\subsubsection{Naïve Method and Snaïve Method}

Company managers or business people occasionally use simple methods to forecast, and these methods can be useful. Using the average value (the mean) of historical data might be useful for time series that fluctuate around some constant value. For a random walk time series, without any trend and seasonality, a naïve method might be useful in which the most recent observation is taken as a forecast for the next period or periods. For a seasonal time series, a Snaïve method might be useful; by which the actual value in the same period of the previous year is taken as a forecast for that period in this year. In measuring the accuracy of forecasting, the naïve or seasonal Snaïve method was used as a reference for that of ETS and ARIMA, because we think that ETS and ARIMA at least should make forecasts with errors as small as naïve or Snaïve method.

\subsubsection{ETS}

The ETS forecasting approach was proposed in the 1950s and used in inventory control [29-31]. The simple ETS has the following form:

$$
\hat{y}_{t+1 \mid t}=\hat{y}_{t \mid t-1}+\alpha\left(y_{t}-\hat{y}_{t \mid t-1}\right) \text {, or } \hat{y}_{t+1 \mid t}=\alpha y_{t}+(1-\alpha) \hat{y}_{t \mid t-1}
$$

where $y_{t}$ is a time series, $\hat{y}_{t \mid t-1}$ is the forecast value for $y_{t}$ by taking account of all previous values, $y_{1}, y_{2}, \ldots, y_{t-1}$, and $\alpha$ is a smoothing parameter between 0 and 1 . For longer-range forecasting by the simple ETS, the forecast formula could be written as $\hat{y}_{t+h \mid t}=\hat{y}_{t+1 \mid t}, h=2,3, \ldots$, where $h$ means $h$ periods ahead [15,32].

The most suitable method for a specific time series varies with trend and seasonality. The trend component includes five possibilities: None (N), Additive (A), Additive damped (Ad), Multiplicative $(\mathrm{M})$, and Multiplicative damped (Md). The seasonal component includes three possibilities: None $(\mathrm{N})$, Additive (A), and Multiplicative (M). By combining the trend and seasonal components, in total, this results in 15 methods. If considering additive and multiplicative error terms, there will be 30 methods. The formulae for recursive calculations and point forecasts have been well summarized and can be accessed openly [32]. The package forest in $\mathrm{R}$ was used in applying exponential smoothing to the three time series, and AIC (Akaike's Information Criterion) corrected, AICc, which is appropriate for small sample bias, was adopted for model selection [32,33]. Finally, the best method was chosen by the lowest AICc value.

\subsubsection{ARIMA}

A time series is weakly stationary if neither the mean nor the autocovariances depend on the time $t$ [34]. Economic time series, such as log price, are usually not stationary because the mean and 
autocovariances sometimes vary with time $t$. When differencing the time series, the resulting time series, which represents the changes in the series, is usually stationary. The original time series is called a unit root process in this case. ARIMA can be used to describe these types of time series. By adding the seasonality, a general form for ARIMA can be described as ARIMA $(p, d, q)(P, D, Q)_{m}$, where $(p, d, q)$ is the non-seasonal part of the model; $(P, D, Q)$ is the seasonal part; $p$ and $P$ are orders of AR (autoregressive part); $d$ and $D$ are the degrees of first differencing; $q$ and $Q$ are orders of MA (moving average part); and $m$ is the number of periods in a year. For monthly prices, $m$ is 12 [14,32].

In this research, we first confirmed the situations of autocorrelation and partial autocorrelation in the time series, which was helpful in choosing the order of AR and MA. Then, we tested stationarity and determined the meaningful degrees of first differencing. We tried the possible orders of AR and MA and degree of integration. The best ARIMA models were selected according to their AICc statistics. However, we stopped at one degree of differencing the time series. Differencing twice makes it difficult to explain the economic meaning of the time series and leads to wider forecasting intervals. The unit root test was implemented to examine the stationarity of both the original time series and the differenced time series. Finally, a diagnostic check of the residuals in ARIMA models was conducted to justify model estimations.

\subsubsection{Forecasting Intervals}

In addition to point forecasts, we need to present forecasting or prediction intervals to show the range of values within which we believe the actual values to fall with some level of probability. Forecasting intervals show the extent of variability and uncertainty, which can be calculated from variances. Under the Gaussian model assumption, the errors are Gaussian and $100 \times(1-\alpha) \%$ forecasting intervals can be calculated by:

$$
\mu_{n+h \mid n} \pm z_{\alpha / 2} \sqrt{\operatorname{var}_{n+h \mid n}}
$$

where $\mu$ is the forecast mean or point forecast at $h$ periods ahead; $z_{\alpha / 2}$ is the $\alpha / 2$ significant point in a Gaussian distribution; and var is variance [15]. As shown in statistics textbooks, when the probability level is $0.95, z$ would be 1.960 ; when the probability level is $0.80, z$ would be 1.282 .

Forecasting intervals become wider when the forecast periods increase because uncertainty increases with time. Error term will not affect the point forecasts because its expectation value is zero, but it plays an important role in calculating variances and forecasting intervals.

\subsubsection{Measures of Forecasting Accuracy}

Forecast error is generally defined as $e_{t}=y_{t}-\hat{y}_{t}$, or the difference between the observation and the forecast at time $t$. This definition is good for one-step forecast. In the case of $h$-periods-ahead forecasts, $\hat{y}_{t+1}, \hat{y}_{t+2}, \ldots, \hat{y}_{t+h}$, it is meaningless if $e_{t}$ is summed because positive and negative errors cancel each other out. Thus, a proper summation of the errors is needed. In our research, three accuracy measures were calculated: RMSE, MAE, and MAPE. The former two are scale-dependent measures, and the last is a percentage point error. Of course, smaller measurement values show more accurate forecasts.

The formulae of these measures are as follows:

$$
\operatorname{RMSE}=\sqrt{\operatorname{mean}\left(e_{t}^{2}\right)} ; \operatorname{MAE}=\operatorname{mean}\left(\left|e_{t}\right|\right) ; \operatorname{MAPE}=\operatorname{mean}\left(\left|100 e_{t} / y_{t}\right|\right)
$$

\section{Results}

\subsection{Seasonal Characteristics}

Seasonality in a time series reflects a pattern of ups and downs over a fixed period of time. In Japan, different regions have different climate characteristics, and each region could have its own 
pattern. The pattern would also affect logging, sawmilling, and the demand for sawnwood, such as demand due to seasonal wood house construction. In the summer season in southern Japan, it is hot and heavy rain can make logging difficult, can damage the road for transportation, and affect the harvest volume. In Northern Japan, rain can be a problem in summer, but in winter, heavy snow leads to lower logging productivity. This pattern of impacts stemming from changes in weather conditions might lead to a seasonal movement in prices for logs. According to industry experts, however, seasonal price fluctuations are most affected by the presence of pests, which damage the quality of logs. Therefore, sawmills try to adjust their log stock and control their acquisition of new logs in spring and summer to avoid or lessen pest damage. Therefore, log prices are low in summer but increase starting from autumn. In contrast, abnormal weather conditions such as extremely heavy snow or rainfall or typhoons affect supply and, thus, prices. When abnormal weather conditions occur, prices will also change due to the related changes impacting supply and demand. These types of price changes should be considered as irregular movements.

Now, we discuss the actual seasonal changes in price for the three species of logs. According to the annual changes against individual months shown in Figures $2 \mathrm{a}$ and $3 \mathrm{a}$, a pattern of decreasing prices in spring to summer and increasing prices from autumn to winter was found for sugi and hinoki across the majority of years examined. For both species, the prices usually reach their lowest point in June and July and start to increase in August. In Figures $2 b, 3 b$ and $4 b$, the changes in mean price values were shown by averaging the subseries of the same month for the years 2002-2015. This figure does not show their magnitude in terms of seasonality because irregular movements were also included, but a general overview can be obtained by their changing mean levels. The means of the prices for sugi and hinoki decreased from February to July and increased from August to October or November; therefore, the prices for both sugi and hinoki are seasonal. As for karamatsu, as shown in Figure 4a,b, no obvious pattern of price fluctuations can be found, though August witnessed the lowest level of mean price, in contrast to the findings for sugi and hinoki. This difference among the three species may be caused by the differences in usage and production areas. As aforementioned, hinoki and sugi sawnwood are mainly used in wood house constructions, but karamatsu sawnwood is mainly used in packaging materials for the transportation of commodities. Wood house construction is seasonal, but other industrial production experiences far less seasonality. Another reason might be the different degree of pest damage. The majority of karamatsu logs are harvested in Hokkaido, which is located in Northern Japan, where summer is short and not intensely hot, and, as such, pest damage is not a serious problem for karamatsu logs.
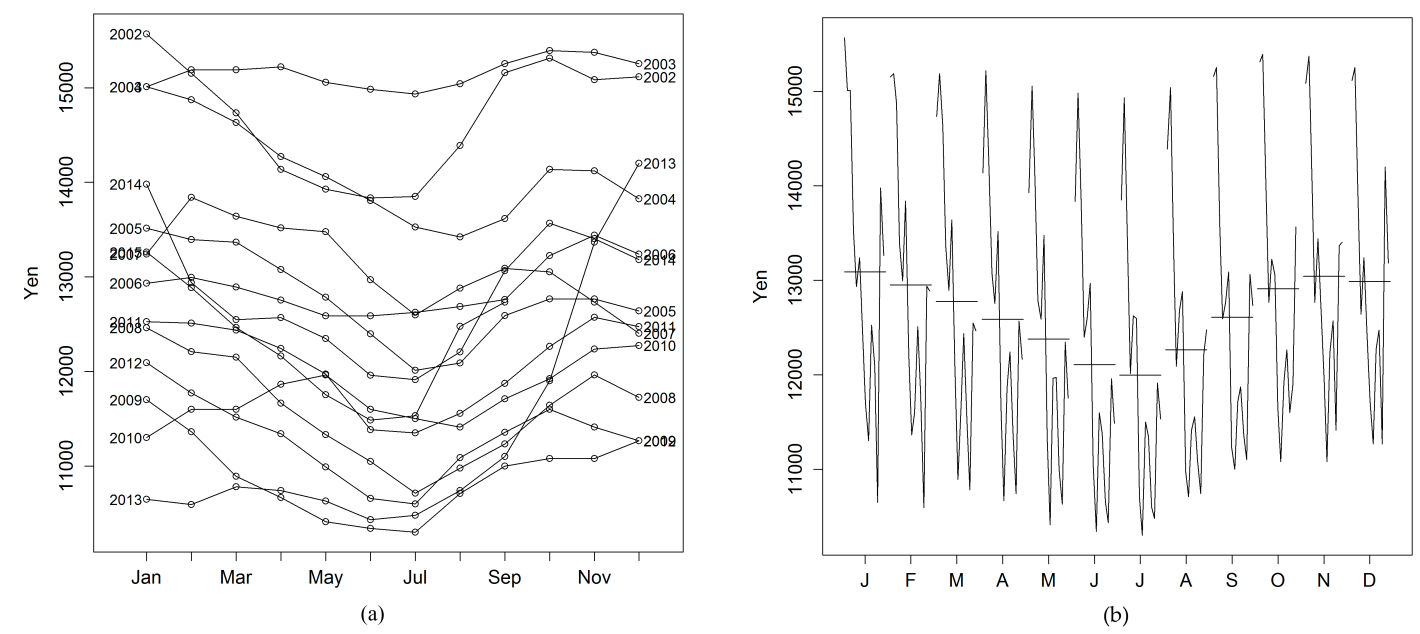

Figure 2. Annual and monthly sugi log prices: (a) Annual changes of sugi log prices against months; (b) monthly subseries of sugi log prices. In Figure 2b, the horizontal bars show the mean prices for the monthly subseries, and polygonal lines show the changes over the years from 2002 to 2015. 

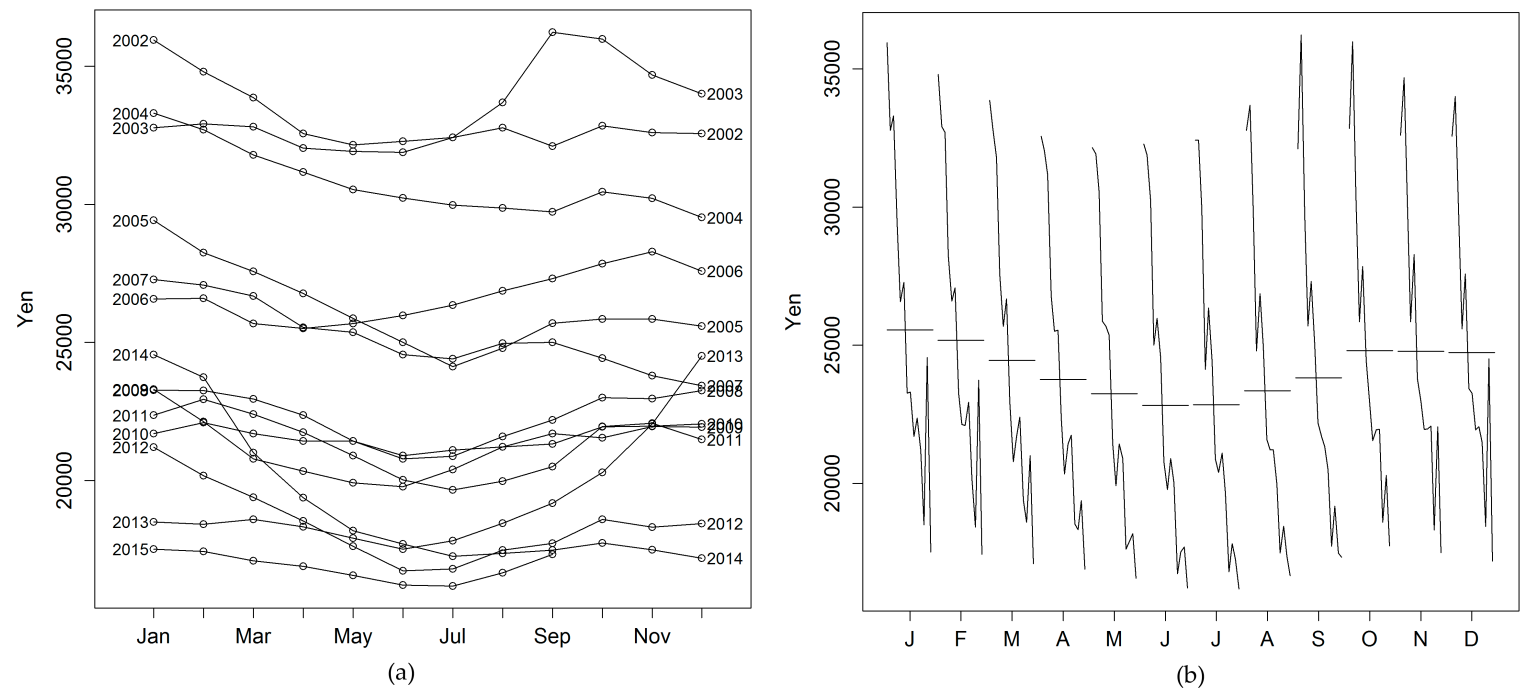

Figure 3. Annual and monthly hinoki log prices: (a) Annual changes of hinoki log prices against months; (b) Monthly subseries of hinoki log prices. In Figure 3b, the horizontal bars show the mean prices for the monthly subseries, and polygonal lines show the changes over the years from 2002 to 2015.
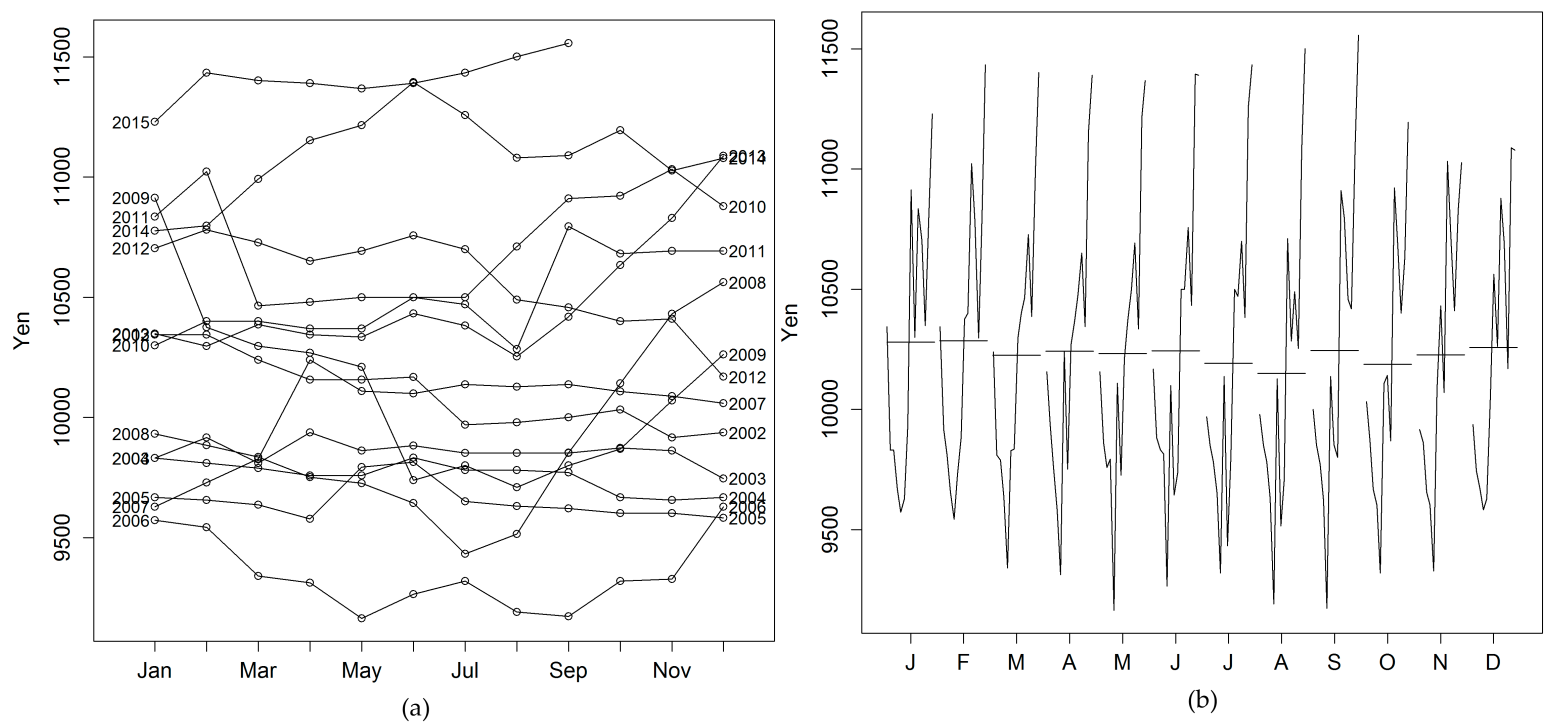

Figure 4. Annual and monthly karamatsu log prices: (a) Annual changes of karamatsu log prices against months; (b) monthly subseries of karamatsu log prices. The horizontal bars show the mean price for the monthly subseries, and polygonal lines show the changes over the years from 2002 to 2015.

\subsection{Trend and Cycles}

The movements for a time series are usually said to be made up of four components-i.e., trend, cyclical, seasonal, and irregular components-but for convenience in short-term forecasting, trend and cycle are usually combined to make trend. Trend is usually defined as a long-term movement (e.g., [35]). As shown in Figures 5-7 sugi, hinoki, and karamatsu each display a different trend. The price for sugi logs experienced a decrease and reached its lowest level during the world financial crisis of 2008-2009. However, its prices started to recover after 2010. In October 2013, the national plan to raise consumption tax from 5\% to 8\% in April 2014 was communicated to the public. Together with the impacts of the devalued yen, which started several months earlier, a rush demand for domestic wood occurred. Thereafter, sugi prices spiked temporarily and then sat at a higher level than those in the years since 2008. In comparison, the price for hinoki logs is still experiencing pressure to decrease. 
There is a decreasing demand for homes having the esthetic appearance of traditional Japanese-style houses in which hinoki wood is required. An increasing amount of laminated wood made of other species is now used in housing construction: this has impacted the price of hinoki logs. In the 1960s, the gap between hinoki and sugi prices grew due to the increasing demand for hinoki. Since 1990, the gap has shrunk. Figure 6 shows a decreasing trend in hinoki log prices. Similar to that of sugi, the hinoki log price rose sharply during the period from October 2013 to January 2014. However, the high prices did not last long. Therefore, the spikes during this time should be considered as an irregular movement. The time series as in Figure 7 showed the karamatsu log price fluctuating with a different pattern. The karamatsu log price also declined after 2002, but it fell to its lowest point in 2006. After 2006, it experienced sharp fluctuations but a recovery could be seen. By September 2015, it had recovered to its price of 2000 .
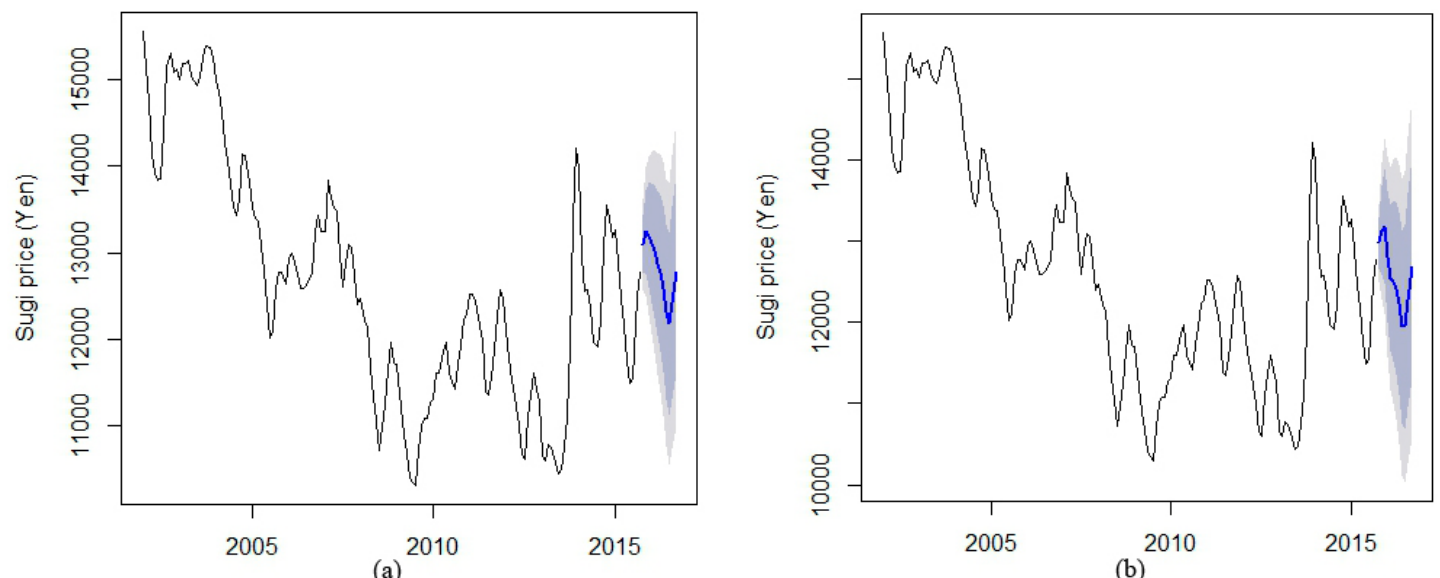

Figure 5. Forecasts of the sugi log prices: (a) Point forecasts and forecast intervals at $80 \%$ and $95 \%$ levels by exponential smoothing method (ETS); (b) point forecasts and forecast intervals at $80 \%$ and 95\% levels by autoregressive integrated moving average (ARIMA).
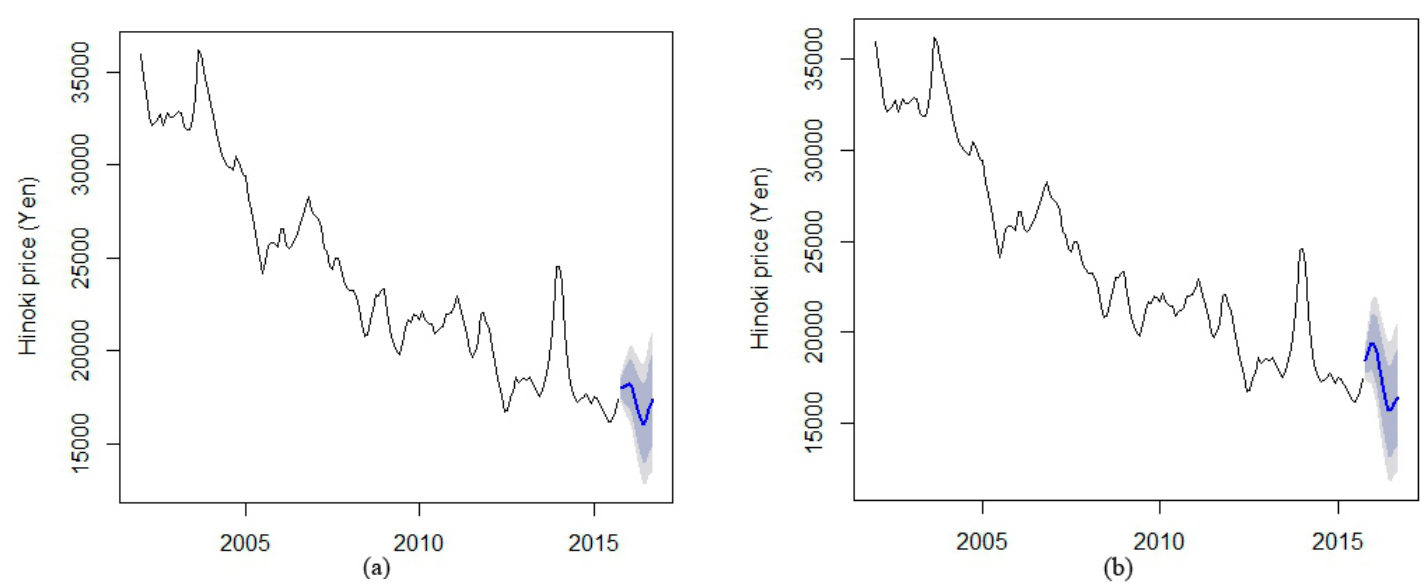

Figure 6. Forecasts of the hinoki log prices: (a) Point forecasts and forecast intervals at $80 \%$ and $95 \%$ levels by ETS; (b) point forecasts and forecast intervals at $80 \%$ and $95 \%$ levels by ARIMA.

Overall, in the long term, hinoki appears to show a decreasing trend, but it is difficult to say that sugi or karamatsu is experiencing a declining, increasing, or converging trend to some constant value. However, if we shorten the period to only recent years, we may find that the mean price is increasing for karamatsu since 2006 and that the mean price in the period since October 2013 is higher than that from 2008 to 2012, implying a recovering trend for sugi. These findings can be obtained by loess-smoothing the trend obtained from decomposing the time series. 


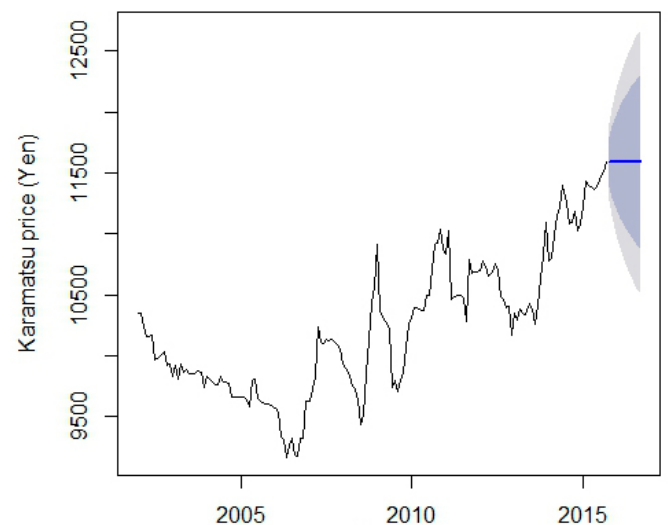

(a)

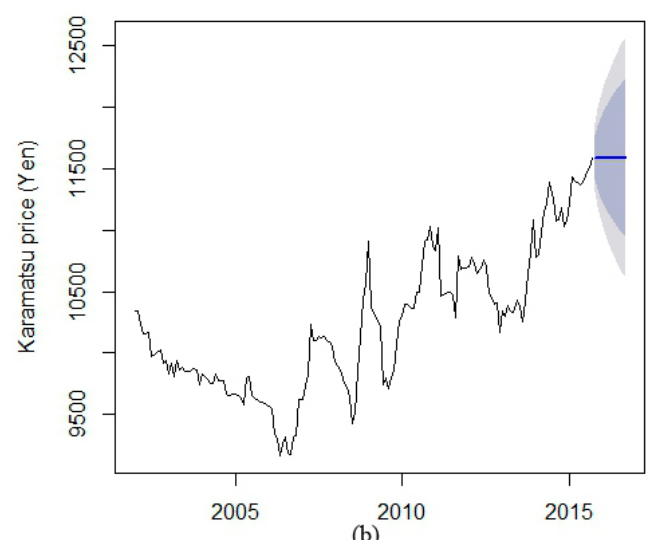

(b)

Figure 7. Forecasts of the karamatsu log prices: (a) Point forecasts and forecast intervals at $80 \%$ and $95 \%$ levels by ETS; (b) point forecasts and forecast intervals at $80 \%$ and $95 \%$ levels by ARIMA.

\subsection{ETS Forecast Results}

In using ets function in the package forecast under the $R$ software environment, the results were shown in the form of (E, T, S), representing the error, trend and season components, respectively. The results for sugi, hinoki and karamatsu log prices are, respectively, $(\mathrm{M}, \mathrm{N}, \mathrm{A}),(\mathrm{M}, \mathrm{Ad}, \mathrm{A})$ and $(\mathrm{M}, \mathrm{N}, \mathrm{N})$. All of these time series have multiplicative errors. Hinoki log price shows a damped trend, whereas sugi and karamatsu display no trend. As for the seasonality, the results show that sugi and hinoki experience additive seasonal movements in prices, but seasonal changes cannot be found in the karamatsu log price, which supports the aforementioned argument regarding seasonal characteristics. The smoothing parameters for sugi are $\alpha=0.9999$ and $\gamma=0.0001$; for hinoki, they are $\alpha=0.9999$, $\beta=0.1412, \gamma=0.0001$, and $\varnothing=0.8007$; and for karamatsu, $\alpha=0.9999$. A high $\alpha$ value shows that time series values are highly affected by the previous value. A small $\gamma$ value shows that the seasonal component does not change much over the years. Given that the expectation of error is zero, both the additive and multiplicative error methods gave the same forecasts but different forecast intervals.

The above estimated parameters can be substituted into the corresponding formulae in the component form [32] to obtain the final models; for sugi, its result for ETS (M, N, A) is as follows:

$$
y_{t}=\left(l_{t-1}+s_{t-m}\right)\left(1+\varepsilon_{t}\right), l_{t}=l_{t-1}+\alpha\left(l_{t-1}+s_{t-m}\right) \varepsilon_{t}, s_{t}=s_{t-m}+\gamma\left(l_{t-1}+s_{t-m}\right) \varepsilon_{t}
$$

For hinoki, ETS (M, Ad, A) is as follows:

$$
\begin{gathered}
y_{t}=\left(l_{t-1}+\varnothing b_{t-1}+s_{t-m}\right)\left(1+\varepsilon_{t}\right), l_{t}=l_{t-1}+\varnothing b_{t-1}+\alpha\left(l_{t-1}+\varnothing b_{t-1}+s_{t-m}\right) \varepsilon_{t}, \\
b_{t}=\varnothing b_{t-1}+\beta\left(l_{t-1}+\varnothing b_{t-1}+s_{t-m}\right) \varepsilon_{t}, s_{t}=s_{t-m}+\gamma\left(l_{t-1}+\varnothing b_{t-1}+s_{t-m}\right) \varepsilon_{t}
\end{gathered}
$$

For karamatsu, ETS $(\mathrm{M}, \mathrm{N}, \mathrm{N})$ is as follows:

$$
y_{t}=l_{t-1}\left(1+\varepsilon_{t}\right) l_{t}=l_{t-1}\left(1+\alpha \varepsilon_{t}\right)
$$

In the formulae, $l_{t}$ stands for the level or smoothed value of the time series at time $t, b$ for slope, $s$ for seasonal component, $m$ for number of periods in a year (here, $m=12), \alpha, \beta, \gamma$ and $\varnothing$ for smoothing parameters, $s_{t-m}$ for the seasonal component for the same month of the previous year. Figures $5 \mathrm{a}, 6 \mathrm{a}$ and $7 \mathrm{a}$ show the results by ETS for sugi, hinoki and karamatsu, respectively, while Figures $5 \mathrm{~b}, 6 \mathrm{~b}$ and $7 \mathrm{~b}$ show the results by ARIMA. The right parts in both sets of figures show the results for the forecasts and the forecast intervals at probability levels of $95 \%$ (wider and brighter shadow area) and $80 \%$ (narrower and darker shadow area), respectively, for the 12 months ahead (see Table 1 for 12-months-ahead forecast and forecast interval values). 
Table 1. Point forecasts and forecast intervals at $80 \%$ and $95 \%$ level. Unit: Yen. ETS, exponential smoothing method; ARIMA, autoregressive integrated moving average.

\begin{tabular}{|c|c|c|c|c|c|c|c|c|c|c|c|}
\hline \multirow{2}{*}{$\log$} & \multirow{2}{*}{ Month } & \multicolumn{5}{|c|}{ ETS } & \multicolumn{5}{|c|}{ ARIMA } \\
\hline & & Point Forecasts & Low $80 \%$ & High $80 \%$ & Low $95 \%$ & High $95 \%$ & Point Forecasts & Low $80 \%$ & High $80 \%$ & Low $95 \%$ & High $95 \%$ \\
\hline \multirow{12}{*}{ Sugi } & 15 October & 13,045 & 12,704 & 13,386 & 12,523 & 13,567 & 12,913 & 12,604 & 13,223 & 12,440 & 13,387 \\
\hline & 15 November & 13,189 & 12,704 & 13,674 & 12,447 & 13,931 & 13,072 & 12,525 & 13,620 & 12,235 & 13,910 \\
\hline & 15 December & 13,151 & 12,556 & 13,746 & 12,241 & 14,061 & 13,129 & 12,427 & 13,832 & 12,055 & 14,204 \\
\hline & 16 January & 13,058 & 12,372 & 13,744 & 12,009 & 14,107 & 12,753 & 11,944 & 13,562 & 11,516 & 13,990 \\
\hline & 16 February & 12,972 & 12,207 & 13,738 & 11,802 & 14,143 & 12,489 & 11,593 & 13,384 & 11,119 & 13,858 \\
\hline & 16 March & 12,827 & 11,991 & 13,663 & 11,549 & 14,106 & 12,442 & 11,466 & 13,418 & 10,949 & 13,935 \\
\hline & 16 April & 12,716 & 11,816 & 13,615 & 11,340 & 14,092 & 12,367 & 11,315 & 13,419 & 10,759 & 13,976 \\
\hline & 16 May & 12,534 & 11,576 & 13,492 & 11,069 & 13,999 & 12,175 & 11,051 & 13,298 & 10,456 & 13,893 \\
\hline & 16 June & 12,260 & 11,249 & 13,270 & 10,715 & 13,804 & 11,888 & 10,697 & 13,079 & 10,067 & 13,709 \\
\hline & 16 July & 12,122 & 11,063 & 13,181 & 10,502 & 13,741 & 11,888 & 10,634 & 13,142 & 9970 & 13,806 \\
\hline & 16 August & 12,368 & 11,261 & 13,476 & 10,675 & 14,062 & 12,213 & 10,899 & 13,527 & 10,203 & 14,222 \\
\hline & 16 September & 12,720 & 11,563 & 13,877 & 10,951 & 14,489 & 12,628 & 11,256 & 13,999 & 10,530 & 14,725 \\
\hline \multirow{12}{*}{ Hinoki } & 15 October & 17,909 & 17,409 & 18,408 & 17,145 & 18,672 & 18,366 & 17,711 & 19,022 & 17,364 & 19,368 \\
\hline & 15 November & 17,989 & 17,207 & 18,772 & 16,792 & 19,187 & 18,804 & 17,691 & 19,917 & 17,102 & 20,507 \\
\hline & 15 December & 18,039 & 17,027 & 19,051 & 16,492 & 19,587 & 19,322 & 17,853 & 20,791 & 17,076 & 21,568 \\
\hline & 16 January & 18,113 & 16,897 & 19,328 & 16,254 & 19,971 & 19,256 & 17,514 & 20,998 & 16,591 & 21,920 \\
\hline & 16 February & 17,952 & 16,553 & 19,351 & 15,812 & 20,092 & 18,848 & 16,894 & 20,803 & 15,859 & 21,838 \\
\hline & 16 March & 17,346 & 15,781 & 18,910 & 14,953 & 19,739 & 17,886 & 15,763 & 20,009 & 14,639 & 21,132 \\
\hline & 16 April & 16,801 & 15,088 & 18,515 & 14,180 & 19,423 & 17,046 & 14,787 & 19,305 & 13,591 & 20,501 \\
\hline & 16 May & 16,336 & 14,486 & 18,186 & 13,507 & 19,166 & 16,261 & 13,889 & 18,633 & 12,633 & 19,889 \\
\hline & 16 June & 15,966 & 13,990 & 17,942 & 12,944 & 18,988 & 15,614 & 13,146 & 18,081 & 11,839 & 19,388 \\
\hline & 16 July & 16,131 & 14,036 & 18,226 & 12,927 & 19,335 & 15,606 & 13,055 & 18,157 & 11,705 & 19,508 \\
\hline & 16 August & 16,758 & 14,545 & 18,971 & 13,374 & 20,142 & 16,041 & 13,416 & 18,665 & 12,027 & 20,054 \\
\hline & 16 September & 17,320 & 14,991 & 19,650 & 13,757 & 20,883 & 16,389 & 13,699 & 19,079 & 12,275 & 20,503 \\
\hline \multirow{12}{*}{ Karamatsu } & 15 October & 11,546 & 11,342 & 11,750 & 11,234 & 11,858 & 11,546 & 11,363 & 11,729 & 11,266 & 11,826 \\
\hline & 15 November & 11,546 & 11,257 & 11,835 & 11,105 & 11,987 & 11,546 & 11,287 & 11,805 & 11,150 & 11,942 \\
\hline & 15 December & 11,546 & 11,193 & 11,899 & 11,005 & 12,087 & 11,546 & 11,229 & 11,863 & 11,061 & 12,031 \\
\hline & 16 January & 11,546 & 11,138 & 11,954 & 10,922 & 12,170 & 11,546 & 11,180 & 11,912 & 10,986 & 12,106 \\
\hline & 16 February & 11,546 & 11,090 & 12,002 & 10,848 & 12,244 & 11,546 & 11,136 & 11,956 & 10,920 & 12,172 \\
\hline & 16 March & 11,546 & 11,046 & 12,046 & 10,781 & 12,311 & 11,546 & 11,097 & 11,995 & 10,860 & 12,232 \\
\hline & 16 April & 11,546 & 11,006 & 12,086 & 10,720 & 12,372 & 11,546 & 11,061 & 12,031 & 10,805 & 12,287 \\
\hline & 16 May & 11,546 & 10,969 & 12,123 & 10,663 & 12,429 & 11,546 & 11,028 & 12,064 & 10,754 & 12,338 \\
\hline & 16 June & 11,546 & 10,934 & 12,158 & 10,609 & 12,483 & 11,546 & 10,996 & 12,096 & 10,706 & 12,386 \\
\hline & 16 July & 11,546 & 10,900 & 12,192 & 10,559 & 12,533 & 11,546 & 10,967 & 12,125 & 10,660 & 12,432 \\
\hline & 16 August & 11,546 & 10,869 & 12,223 & 10,511 & 12,581 & 11,546 & 10,938 & 12,154 & 10,617 & 12,475 \\
\hline & 16 September & 11,546 & 10,839 & 12,253 & 10,464 & 12,628 & 11,546 & 10,911 & 12,181 & 10,576 & 12,516 \\
\hline
\end{tabular}




\subsection{ARIMA Forecast Results}

These three time series are not stationary, as shown by their actual values in their left parts in either both sets of figures; their levels changed and did not converge to some constant value. The Augmented Dickey-Fuller (ADF) test, a unit root test, was implemented [36,37]. Package tseries in $R$ was used in which the null hypothesis is that the time series has a unit root and is not stationary, and an alternative hypothesis we adopted in this case study is that it is "stationary". For sugi, Dickey-Fuller $=-1.860$ $(p$-value $=0.635)$; after differencing, Dickey-Fuller $=-7.142$ ( $p$-value $<0.01)$. For hinoki, Dickey-Fuller $=-2.655$ ( $p$-value $=0.303)$; after differencing, Dickey-Fuller $=-6.918(p$-value $<0.01)$. For karamatsu, Dickey-Fuller $=-3.252$ ( $p$-value $=0.082)$; after differencing, Dickey-Fuller $=-6.307$ ( $p$-value $<0.01)$. $p$-values above 0.05 in the ADF tests for the original time series show that the null hypothesis that original time series is not stationary and cannot be rejected by a $5 \%$ significant level, i.e., providing no evidence against the need for differencing, but that after differencing, $p$-values become less than 0.01 , showing that further integration of a 2 nd order can be rejected, and the 1st differences become stationary at a $1 \%$ significance level. That is, a degree of one is suitable for the integrated part of the ARIMA models.

By implementing the Arima function in the package forecast, we obtained the following result for sugi as the best model due to its lowest AICc: ARIMA $(2,1,0)(2,1,1)$, representing two non-seasonal autoregressive terms, two seasonal autoregressive terms, and one seasonal moving averages term. Their coefficients and standard errors are, respectively, $0.457(0.079),-0.245(0.085),-0.595(0.145)$, $-0.441(0.118)$, and $-0.367(0.165)$. All of them are significant at a $1 \%$ significance level, though in forecasting, it is not important to pursue significance parameters. When summarizing this result, the following model can be obtained.

$$
\begin{gathered}
\mathrm{Y}_{t}=1.457 \mathrm{Y}_{t-1}-0.702 \mathrm{Y}_{t-2}+0.245 \mathrm{Y}_{t-3}+0.405 \mathrm{Y}_{t-12}-0.590 \mathrm{Y}_{t-13}+0.284 \mathrm{Y}_{t-14}- \\
0.099 \mathrm{Y}_{t-15}+0.154 \mathrm{Y}_{t-24}-0.224 \mathrm{Y}_{t-25}+0.108 \mathrm{Y}_{t-26}-0.038 \mathrm{Y}_{t-27}+0.441 \mathrm{Y}_{t-36}- \\
0.643 \mathrm{Y}_{t-37}+0.310 \mathrm{Y}_{t-38}-0.108 \mathrm{Y}_{t-39}+e_{t}-0.367 e_{t-12}
\end{gathered}
$$

By fitting it into the ARIMA model, we obtained the best hinoki $\log$ price model as ARIMA $(2,1,1)$ $(0,1,2)$, with two non-seasonal autoregressive terms, one non-seasonal moving average term, and two seasonal moving average terms. Their coefficients and standard errors are: $1.306(0.087),-0.398(0.076)$, $-0.932(0.057),-1.104(0.092)$, and $0.352(0.109)$. All of these parameters are also significant at a $1 \%$ significance level. The model is as follows:

$$
\begin{gathered}
\mathrm{Y}_{t}=2.306 \mathrm{Y}_{t-1}-1.704 \mathrm{Y}_{t-2}+0.398 \mathrm{Y}_{t-3}+\mathrm{Y}_{t-12}-2.306 \mathrm{Y}_{t-13}+1.704 \mathrm{Y}_{t-14}-0.398 \mathrm{Y}_{t-15}+ \\
e_{t}-0.932 e_{t-1}-1.104 e_{t-12}+1.029 e_{t-13}+0.352 e_{t-24}-0.328 e_{t-25}
\end{gathered}
$$

The best karamatsu log price model has the form as ARIMA $(0,1,0)$, with no seasonal terms, autoregressive terms, or moving average terms. This type of time series is usually called a random walk [35]. The model can be written as:

$$
\mathrm{Y}_{t}=\mathrm{Y}_{t-1}+e_{t}
$$

\subsection{Diagnostic Check of Residuals in ARIMA Models}

Finally, we need to verify the adequacy of our ARIMA models by checking their residuals. By fitting a model, we can obtain fitted values and residuals. For a forecasting model, we have observed values and forecasts based on previous observed values, and the differences are residuals: $e_{t}=y_{t}-\hat{y}_{t}$. Residuals should have two properties: uncorrelated and zero mean [32]. Correlations between residuals mean that the model is not fitted well because patterns remained in the residuals and should be included in the model. In addition, if the mean of residuals is not zero, then the forecasts are biased. It would be better also to check two other properties for ideal residuals: constant variance and normal distribution [32]. 
For the three ARIMA models, we first checked residuals' correlations. Figure 8 shows residuals and their autocorrelations and partial autocorrelations with lags of up to 36 for the sugi log price. No pattern can be found in Figure 8a, though some irregular residuals existed. Figure 8b,c show that no significant correlations were confirmed. The situations for hinoki were similar. Figure 9 showed the analysis of the prices for karamatsu logs. Similarly, some irregular residuals were found in Figure 9a, but no pattern was confirmed. Two significant autocorrelations and partial correlations, respectively, were found by checking Figure $9 b, c$ but most of them with a lag over 20. This result can be ignored by considering it an accidental result. We then implemented an ADF test, and the Dickey-Fuller results were $-5.992,-5.360$, and -6.283 , respectively, for sugi, hinoki, and karamatsu. For all of the cases, $p$-value $<0.01$, which shows that they are stationary. Finally, we implemented the Box-Ljung test [38]. The results for sugi, hinoki, and karamatsu are $\chi^{2}=22.660(p$-value $=0.540), 15.874(p$-value $=0.893)$, and $32.014(p$-value $=0.127)$, which means that these residuals were not distinguishable from a white noise series.

(a)
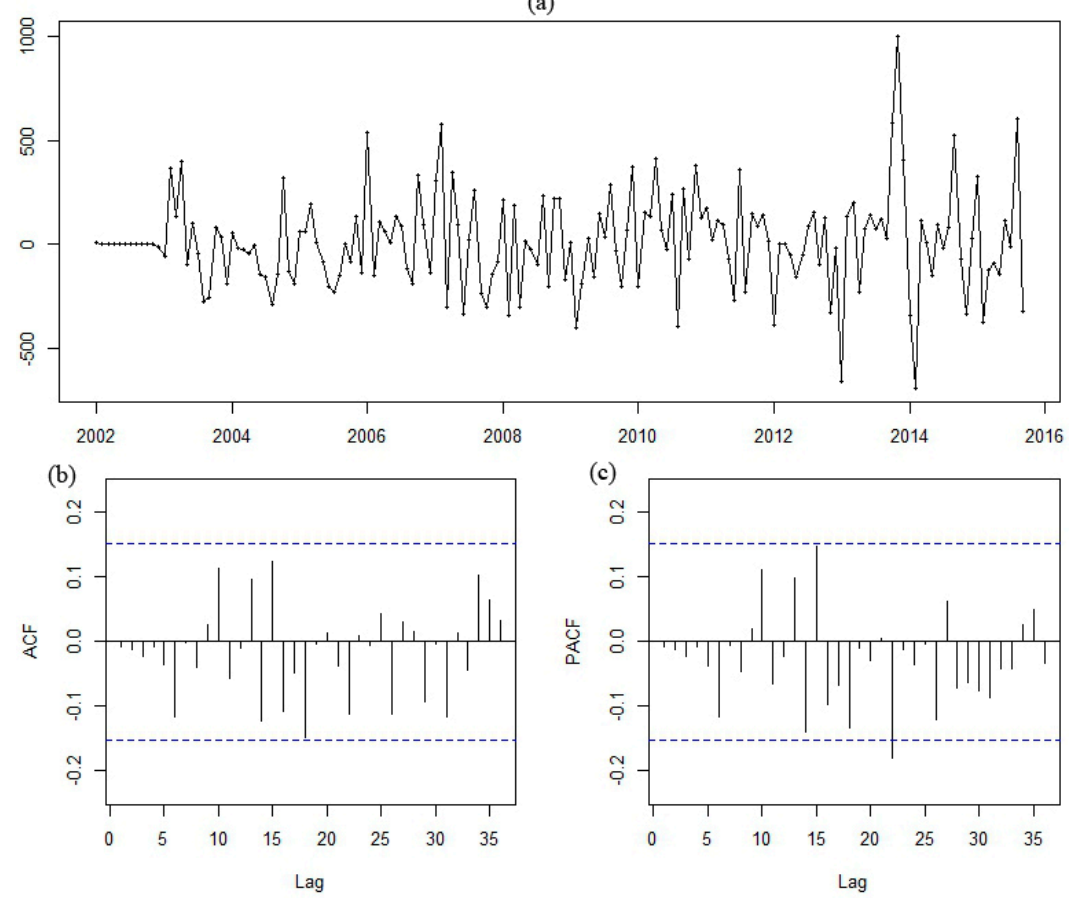

Figure 8. Residuals and their autocorrelations in sugi ARIMA model: (a) Plot of residuals; (b) autocorrelations with lags of up to 36 for the sugi log prices; (c) partial autocorrelations with lags of up to 36 for the sugi log prices.

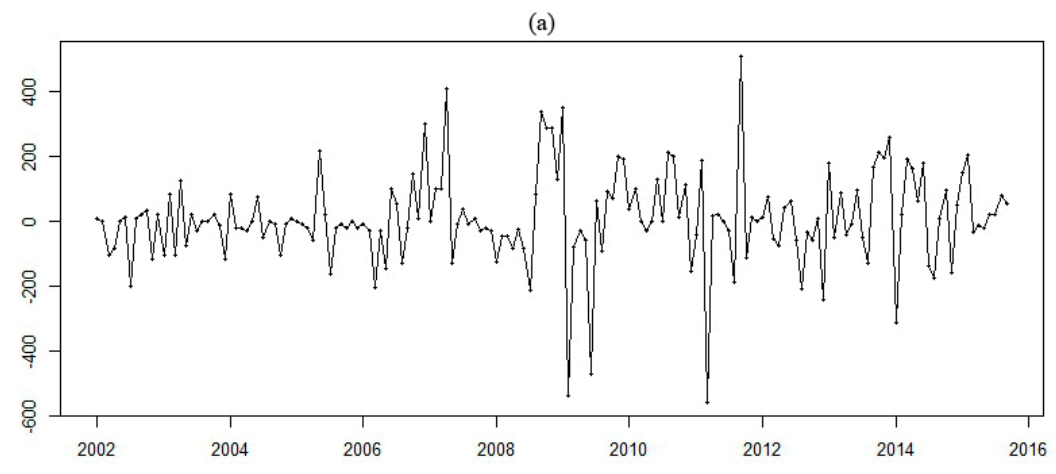

Figure 9. Cont. 

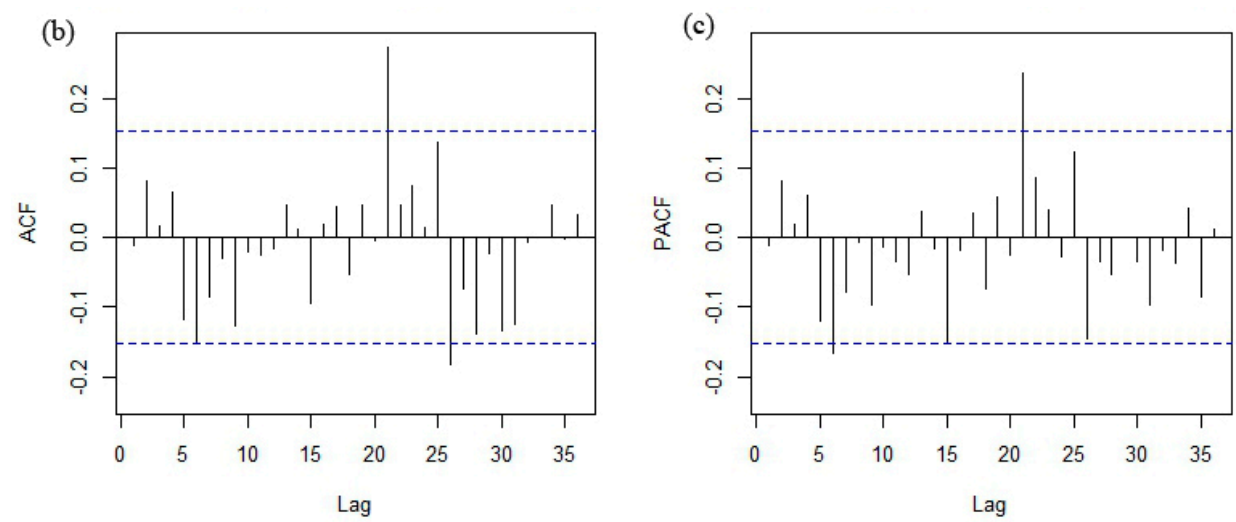

Figure 9. Residuals and their autocorrelations in karamatsu ARIMA model: (a) Plot of residuals; (b) autocorrelations with lags of up to 36 for the sugi log prices; (c) partial autocorrelations with lags of up to 36 for the sugi log prices.

\subsection{Measuring the Accuracy of Forecasts}

To measure the forecast accuracy, we divided our data set into two parts: sample data and out-of-sample data. We dealt with two forecast periods here: 12 months and 6 months. We established the objective of the research as being to forecast monthly prices and acknowledged the forecasting as being short-term; therefore, being able to forecast one year ahead or some months (less than 12 months) ahead accurately is important. The errors for forecasting sugi, hinoki, and karamatsu log prices for 12 months ahead by ETS and ARIMA were shown in Table 2. As for other lengths, from one to five months, from seven to 11 months, the results for sugi and hinoki were shown in supplementary materials (Tables S1-S10).

Table 2 shows 10 valuations of forecast errors of 12-months-ahead forecasts. Firstly, data from October 2014 to September 2015 were taken as out-of-sample data, while the data from January 2002 to September 2014 were taken as sample data. In the next nine valuations, by keeping 12 months as the forecast period and deleting the last datum in the series every time and moving backward, we obtained nine sets of sample data and out-of-sample data. Thus, the second sample data were from January 2002 to August 2014, and out-of-sample data were from September 2014 to August 2015. Snaïve was used for sugi and hinoki accuracy valuations, but a naïve method was used for karamatsu because the karamatsu log price did not show obvious seasonality.

As shown in Table 2, MAPE, MAE, and RMSE have similar results in comparing the accuracy of forecasts among ETS, ARIMA, and Snaïve method to sugi and hinoki or naïve method to karamatsu; i.e., when MAPE value is the smallest for a method among the three methods, MAE and RMSE values are also smallest for this method. Valuation 1 was the case in which the most recent sample data and out-of-sample data were used. For the sugi log price, ETS had a smaller error than ARIMA, but both ETS and ARIMA had larger errors than the Snaïve method. The results showed the error ranged from $3.96 \%$ to $5.57 \%$ by MAPE, from 504 Yen to 685 Yen by MAE, and from 670 Yen to 748 Yen by RMSE. For the hinoki log price in Valuation 1, its forecast accuracy was much better. The smallest forecast errors were from ARIMA, which were $1.64 \%$ by MAPE, 282 Yen by MAE, and 332 Yen by RMSE. The ETS results were not as good as those of ARIMA but were better than those of the Snaïve method. As for the karamatsu log price in Valuation 1, ETS and ARIMA resulted in the same errors as the naïve method.

By comparing the errors for sugi and hinoki over 10 valuations, Valuations 9 and 10 gave the largest errors due to the impact of the irregular level of prices at the end of 2013. Among the 10 valuations, it can be found that for sugi, ETS had smaller errors twice (i.e., for Valuations 1 and 8); for hinoki, ETS had a better error only once (i.e., for Valuation 4); and in all other cases ARIMA showed smaller errors for sugi and hinoki. As for karamatsu, ETS and ARIMA had the same errors as those by naïve method, except in the two valuations due to the rounding errors (i.e., Valuations 7 and 9). 
Table 2. Forecast errors for 12-months-ahead forecasts. "Kara." stands for karamatsu. The smallest error among the three methods is shown in bold letters. Snaïve method is applied to sugi and hinoki, while the naïve method to karamatsu. MAPE, mean absolute percentage error; MAE, mean absolute error; RMSE, root mean square error.

\begin{tabular}{|c|c|c|c|c|c|c|c|c|c|c|}
\hline \multirow{2}{*}{\multicolumn{2}{|c|}{ Valuations - }} & \multicolumn{3}{|c|}{ MAPE (\%) } & \multicolumn{3}{|c|}{ MAE (Yen) } & \multicolumn{3}{|c|}{ RMSE (Yen) } \\
\hline & & Snaïve/Naïve & ETS & ARIMA & Snaïve/Naïve & ETS & ARIMA & Snaïve/Naïve & ETS & ARIMA \\
\hline \multirow{3}{*}{1} & Sugi & 3.96 & 4.77 & 5.57 & 504 & 578 & 685 & 670 & 697 & 748 \\
\hline & Hinoki & 19.01 & 3.25 & 1.64 & 3273 & 545 & 282 & 4065 & 626 & 332 \\
\hline & Kara. & 2.20 & 2.20 & 2.20 & 252 & 252 & 252 & 285 & 285 & 285 \\
\hline \multirow{3}{*}{2} & Sugi & 4.99 & 3.33 & 2.37 & 639 & 416 & 300 & 872 & 457 & 347 \\
\hline & Hinoki & 19.74 & 2.44 & 1.74 & 3401 & 418 & 301 & 4094 & 479 & 378 \\
\hline & Kara. & 1.93 & 1.93 & 1.93 & 220 & 220 & 220 & 261 & 261 & 261 \\
\hline \multirow{3}{*}{3} & Sugi & 5.82 & 3.24 & 2.26 & 740 & 407 & 289 & 967 & 455 & 360 \\
\hline & Hinoki & 19.90 & 3.29 & 2.52 & 3432 & 571 & 436 & 4101 & 708 & 516 \\
\hline & Kara. & 1.26 & 1.26 & 1.26 & 142 & 142 & 142 & 151 & 151 & 151 \\
\hline \multirow{3}{*}{4} & Sugi & 6.53 & 3.33 & 2.05 & 825 & 426 & 263 & 1045 & 498 & 342 \\
\hline & Hinoki & 19.60 & 5.45 & 8.84 & 3386 & 940 & 1523 & 4091 & 1035 & 1577 \\
\hline & Kara. & 1.42 & 1.42 & 1.42 & 158 & 158 & 158 & 208 & 208 & 208 \\
\hline \multirow{3}{*}{5} & Sugi & 7.25 & 2.75 & 2.38 & 913 & 354 & 309 & 1126 & 429 & 395 \\
\hline & Hinoki & 18.92 & 14.06 & 6.07 & 3278 & 2429 & 1051 & 4069 & 2607 & 1139 \\
\hline & Kara. & 1.17 & 1.17 & 1.17 & 132 & 132 & 132 & 147 & 147 & 147 \\
\hline \multirow{3}{*}{6} & Sugi & 7.98 & 2.32 & 1.74 & 1007 & 301 & 225 & 1218 & 373 & 284 \\
\hline & Hinoki & 18.23 & 15.43 & 7.50 & 3166 & 2678 & 1304 & 4043 & 2977 & 1442 \\
\hline & Kara. & 1.19 & 1.19 & 1.19 & 135 & 135 & 135 & 160 & 160 & 160 \\
\hline \multirow{3}{*}{7} & Sugi & 8.92 & 2.64 & 1.60 & 1125 & 346 & 211 & 1323 & 445 & 319 \\
\hline & Hinoki & 17.46 & 15.54 & 8.20 & 3046 & 2720 & 1432 & 3990 & 2854 & 1592 \\
\hline & Kara. & 1.95 & 1.96 & 1.95 & 220 & 221 & 220 & 257 & 258 & 257 \\
\hline \multirow{3}{*}{8} & Sugi & 10.04 & 3.17 & 3.43 & 1266 & 400 & 444 & 1418 & 456 & 512 \\
\hline & Hinoki & 16.51 & 34.81 & 22.13 & 2922 & 6161 & 3926 & 3890 & 6397 & 4029 \\
\hline & Kara. & 3.39 & 3.39 & 3.39 & 380 & 380 & 380 & 402 & 402 & 402 \\
\hline \multirow{3}{*}{9} & Sugi & 11.51 & 12.42 & 5.86 & 1457 & 1571 & 738 & 1571 & 1588 & 782 \\
\hline & Hinoki & 15.37 & 40.29 & 24.09 & 2841 & 7177 & 4305 & 3767 & 7642 & 4520 \\
\hline & Kara. & 3.11 & 3.10 & 3.11 & 348 & 346 & 348 & 377 & 375 & 377 \\
\hline \multirow{3}{*}{10} & Sugi & 13.05 & 16.79 & 12.67 & 1675 & 2125 & 1602 & 1830 & 2204 & 1653 \\
\hline & Hinoki & 14.08 & 65.79 & 30.81 & 2759 & 11,862 & 5573 & 3622 & 12,709 & 5931 \\
\hline & Kara. & 1.16 & 1.16 & 1.16 & 129 & 129 & 129 & 170 & 170 & 170 \\
\hline
\end{tabular}

MAPE, MAE, and RMSE are metrics that are used to summarize the errors for the whole forecast periods. When changing the length of forecast periods, the results expressed by these metrics might also change. Forecasters occasionally need to know the forecast for the next 6 months rather than the next 12 ones. Hence, we also measured the accuracy of forecasts in 6-months-ahead forecasts 10 times. Similarly, we kept the length of 6 months for out-of-sample data and, for each time, deleted the last datum and moved the dataset backward to obtain a new dataset. Similarly to the results in Table 2, in the majority of cases of 6-months-ahead forecasts for sugi and hinoki log prices, ARIMA had smaller errors than ETS and, as for the karamatsu log prices, ETS and ARIMA had the same errors as those obtained when using the naïve method (Table 3). Similarly, the errors from the earliest sample data for hinoki by ARIMA, as shown in Valuation 10, were also high compared with other valuations for hinoki by ARIMA: $9.18 \%$ by MAPE, 1602 Yen by MAE, and 1680 Yen by RMSE. 
Table 3. Forecast errors for 6-months-ahead forecasts. "Kara." stands for karamatsu. The smallest error among the three methods are shown in bold letters. Snaïve method is applied to sugi and hinoki, while naïve method to karamatsu.

\begin{tabular}{|c|c|c|c|c|c|c|c|c|c|c|}
\hline \multirow{2}{*}{\multicolumn{2}{|c|}{ Valuations }} & \multicolumn{3}{|c|}{ MAPE (\%) } & \multicolumn{3}{|c|}{ MAE (Yen) } & \multicolumn{3}{|c|}{ RMSE (Yen) } \\
\hline & & Snaïve/Naïve & ETS & ARIMA & Snaïve/Naïve & ETS & ARIMA & Snaïve/Naïve & ETS & ARIMA \\
\hline \multirow{3}{*}{1} & Sugi & 3.47 & 2.87 & 2.25 & 414 & 345 & 273 & 427 & 362 & 299 \\
\hline & Hinoki & 7.63 & 2.34 & 2.99 & 1264 & 388 & 496 & 1460 & 409 & 521 \\
\hline & Kara. & 0.44 & 0.44 & 0.44 & 50 & 50 & 50 & 71 & 71 & 71 \\
\hline \multirow{3}{*}{2} & Sugi & 3.13 & 4.09 & 2.63 & 370 & 483 & 312 & 404 & 519 & 330 \\
\hline & Hinoki & 11.29 & 4.54 & 1.46 & 1889 & 751 & 240 & 2162 & 776 & 284 \\
\hline & Kara. & 0.39 & 0.39 & 0.39 & 44 & 44 & 44 & 44 & 46 & 46 \\
\hline \multirow{3}{*}{3} & Sugi & 2.85 & 6.33 & 6.70 & 336 & 752 & 798 & 391 & 791 & 821 \\
\hline & Hinoki & 16.58 & 5.92 & 1.12 & 2817 & 980 & 187 & 3345 & 1057 & 221 \\
\hline & Kara. & 1.49 & 1.49 & 1.49 & 170 & 170 & 170 & 171 & 171 & 171 \\
\hline \multirow{3}{*}{4} & Sugi & 3.17 & 4.12 & 2.83 & 388 & 493 & 344 & 460 & 567 & 372 \\
\hline & Hinoki & 22.13 & 7.12 & 2.09 & 3806 & 1194 & 350 & 4387 & 1294 & 404 \\
\hline & Kara. & 2.54 & 2.54 & 2.54 & 290 & 290 & 290 & 297 & 297 & 297 \\
\hline \multirow{3}{*}{5} & Sugi & 3.78 & 3.99 & 2.16 & 480 & 487 & 268 & 590 & 599 & 311 \\
\hline & Hinoki & 27.70 & 4.72 & 1.91 & 4779 & 798 & 325 & 5274 & 958 & 356 \\
\hline & Kara. & 2.55 & 2.55 & 2.55 & 290 & 290 & 290 & 315 & 315 & 315 \\
\hline \multirow{3}{*}{6} & Sugi & 2.98 & 5.06 & 3.70 & 387 & 641 & 472 & 538 & 705 & 513 \\
\hline & Hinoki & 30.42 & 2.54 & 2.08 & 5268 & 434 & 359 & 5553 & 563 & 395 \\
\hline & Kara. & 1.44 & 1.44 & 1.44 & 163 & 163 & 163 & 177 & 177 & 177 \\
\hline \multirow{3}{*}{7} & Sugi & 4.45 & 2.59 & 4.08 & 594 & 333 & 531 & 847 & 398 & 579 \\
\hline & Hinoki & 30.38 & 1.59 & 2.25 & 5282 & 275 & 392 & 5560 & 332 & 422 \\
\hline & Kara. & 1.42 & 1.42 & 1.42 & 161 & 161 & 161 & 203 & 203 & 203 \\
\hline \multirow{3}{*}{8} & Sugi & 6.84 & 2.86 & 2.58 & 907 & 381 & 342 & 1166 & 434 & 402 \\
\hline & Hinoki & 28.19 & 3.27 & 2.41 & 4914 & 570 & 421 & 5371 & 610 & 478 \\
\hline & Kara. & 0.99 & 0.99 & 0.99 & 112 & 112 & 112 & 164 & 164 & 164 \\
\hline \multirow{3}{*}{9} & Sugi & 8.78 & 3.28 & 2.82 & 1143 & 436 & 374 & 1310 & 491 & 455 \\
\hline & Hinoki & 23.22 & 4.97 & 3.23 & 4046 & 867 & 564 & 4737 & 928 & 634 \\
\hline & Kara. & 1.28 & 1.28 & 1.28 & 142 & 142 & 142 & 158 & 158 & 158 \\
\hline \multirow{3}{*}{10} & Sugi & 9.88 & 3.81 & 2.06 & 1262 & 502 & 274 & 1405 & 577 & 393 \\
\hline & Hinoki & 17.07 & 4.54 & 9.18 & 2967 & 793 & 1602 & 3772 & 909 & 1680 \\
\hline & Kara. & 2.47 & 2.47 & 2.47 & 274 & 274 & 274 & 285 & 285 & 285 \\
\hline
\end{tabular}

ETS and ARIMA occasionally give rather different forecast results as shown in Table 1. It is difficult to say which method is definitively better than the other, even though ARIMA makes forecasts with smaller errors in most cases in this research. Therefore, in order to find a method by which we can forecast prices with smaller errors, we attempted another method in which we combined the forecasts from ETS and ARIMA to obtain average point forecasts for sugi and hinoki. Karamatsu is not dealt with because it is a random walk, and ETS and ARIMA gave the same point forecasts with the naïve method. The forecast errors by using this combined method are shown in Table 4 . For 12-months-ahead forecasts, in Valuations 4, 5, and 6 for hinoki log prices and Valuation 8 for sugi log prices, the errors by the combined method were the smallest among Snaïve, ETS, ARIMA, which are shown in Table 2, and this combined method is based on all three error metrics. For 6-months-ahead forecasting, in Valuations 10 for the hinoki log price, the results from the combined method were the best based on all three error metrics. For most cases, errors from the combined method were found to fall between those observed for ETS and ARIMA models. In other words, the forecasts using the combined method were not the worst forecasts and were occasionally better than both the ETS and ARIMA forecasts. 
Table 4. Forecast errors using average method for 12- and 6-months ahead forecasts.

\begin{tabular}{cccccccc}
\hline \multirow{2}{*}{ Valuations } & \multicolumn{2}{c}{ 12-Months-Ahead } & \multicolumn{2}{c}{ 6-Months-Ahead } \\
\cline { 3 - 8 } & & MAPE & MAE & RMSE & MAPE & MAE & RMSE \\
\hline \multirow{2}{*}{1} & Sugi & 5.09 & 620 & 714 & 2.56 & 309 & 329 \\
& Hinoki & 2.18 & 369 & 414 & 2.66 & 442 & 456 \\
\hline \multirow{2}{*}{2} & Sugi & 2.85 & 357 & 394 & 3.36 & 398 & 421 \\
& Hinoki & 1.96 & 337 & 409 & 2.85 & 469 & 509 \\
\hline \multirow{2}{*}{3} & Sugi & 2.72 & 344 & 398 & 6.52 & 775 & 805 \\
& Hinoki & 2.91 & 503 & 604 & 2.88 & 475 & 552 \\
\hline \multirow{2}{*}{4} & Sugi & 2.66 & 342 & 415 & 3.32 & 399 & 461 \\
& Hinoki & $\mathbf{1 . 7 0}$ & $\mathbf{2 9 3}$ & $\mathbf{3 2 3}$ & 4.61 & 772 & 836 \\
\hline \multirow{2}{*}{5} & Sugi & 2.42 & 314 & 400 & 2.76 & 337 & 422 \\
& Hinoki & $\mathbf{4 . 1 6}$ & $\mathbf{7 1 8}$ & $\mathbf{7 6 8}$ & 3.23 & 548 & 640 \\
\hline \multirow{2}{*}{6} & Sugi & 1.99 & 258 & 320 & 4.38 & 556 & 605 \\
& Hinoki & $\mathbf{4 . 0 2}$ & $\mathbf{6 9 8}$ & $\mathbf{7 9 7}$ & $\mathbf{2 . 0 2}$ & $\mathbf{3 4 6}$ & 431 \\
\hline \multirow{2}{*}{7} & Sugi & 2.07 & 273 & 374 & 3.17 & 410 & 471 \\
& Hinoki & 11.87 & 2076 & 2216 & $\mathbf{1 . 5 7}$ & $\mathbf{2 7 4}$ & 337 \\
\hline \multirow{2}{*}{8} & Sugi & $\mathbf{1 . 2 6}$ & $\mathbf{1 6 3}$ & $\mathbf{2 1 3}$ & 2.71 & 360 & 413 \\
& Hinoki & 28.47 & 5043 & 5211 & 2.84 & 496 & 537 \\
\hline \multirow{2}{*}{9} & Sugi & 9.14 & 1155 & 1176 & 3.05 & 405 & 471 \\
& Hinoki & 32.19 & 5741 & 6077 & 4.10 & 715 & 775 \\
\hline \multirow{2}{*}{10} & Sugi & 14.73 & 1863 & 1922 & 2.91 & 385 & 477 \\
& Hinoki & 48.30 & 8717 & 9317 & $\mathbf{2 . 3 4}$ & $\mathbf{4 0 8}$ & $\mathbf{4 1 0}$ \\
\hline \multirow{4}{*}{} & & & & & & & \\
\hline
\end{tabular}

\section{Discussion}

As the saying goes, all forecasts are wrong, but some might be useful. In this research, we used the national average log price data of sugi, hinoki, and karamatsu; ETS and ARIMA methods; and the package forecast in software $R$ [16]. We checked the seasonality, the trend, and obtained 12-months-ahead forecasts for sugi, hinoki, and karamatsu. The fact that Japanese sugi and hinoki log prices are seasonal but karamatsu prices are not is well reflected in the ETS and ARIMA models. In most cases, ARIMA gave better results than ETS for sugi and hinoki. These findings are useful for the short-term forecasting of Japanese domestic log prices. Actually, though ETS and ARIMA adopt different modeling and estimation strategies and algorithms, additive error ETS models are all special cases of ARIMA models, while the non-linear ETS models cannot find equivalents in ARIMA [32]. Our ETS models all have multiplicative errors; therefore, the best models by ETS and ARIMA in this case do not have equivalents to each other. For karamatsu log prices, the forecasts by ETS and ARIMA are the same as the ones by the naïve method, but their forecasting intervals are different.

Because forecasting deals with stochastic issues, no one can be sure about their forecasts. Showing forecasting intervals is a good way to reflect the extent of possible variations. If actual prices are approaching the upper or lower limits, this should raise a high alert in terms of risk management. Providing such data would be useful to avoid the mismatch between supply and demand and, thus, the sharp fall or rise of log prices.

This research used univariate time series analysis for forecasting. Sometimes, structural time series models are useful for forecasting, as they incorporate terms of interest into the model, though one has to forecast or assume those terms first. In the case of forecasting price, however, it becomes complicated. According to economics theory, the price of a commodity is an endogenous variable that is determined by the relationship between supply and demand in the market. Price shifts with the changes in income, consumers' preferences, cost of production elements, technological changes, prices of other related commodities, among other factors. Prices can be forecasted by taking these 
factors into account. For example, Organization of the Petroleum Exporting Countries (OPEC) quota, OPEC production, and industrial stock level of oil can be used to forecast short-term oil price [39]. However, there are not many empirical studies on price forecasting by using structural time series models, perhaps due to the difficulties in quantifying the related factors and those factors must be forecasted prior to forecasting prices. With univariate forecasting approaches, the only variable is $\log$ price in this research, which makes forecasting simple and sometimes useful. Of course, the ETS method simply decomposes a time series into trend, seasonal, and error components without taking other elements into account, such as cyclical movements. As for ARIMA models, it might be a good idea to add exogenous variables to the model $[40,41]$. Furthermore, it is also worthwhile to apply equilibrium, structural, and reduced form models in forecasting the prices of Japanese logs.

Abenomics, a policy that went into effect in Japan in December 2012, ensured that corrections to the excessive yen appreciation were made. In addition, when the plan to raise consumption tax from $5 \%$ to $8 \%$ in April 2014 was communicated to the public in October 2013, a spike in demand for wood house construction led to sharp increases in sugi and hinoki log prices from October 2013 to January 2014. After this period, hinoki log prices dropped to their earlier level, whereas sugi log prices dropped and fluctuated at a higher level than previously. These contextual changes made short-term forecasts from this specific period uncertain. Fortunately, concerns that increased tax would case an economic recession have not become a reality. These price fluctuations in sugi and hinoki can be taken as irregular movements. That is, the structural changes in the logs market in Japan have not occurred.

However, any factors that affect demand and supply, including any changes in the international and domestic economic environment, might affect prices. The impact of the increase in consumption tax (from $8 \%$ to $10 \%$ ) in the near future and fluctuations in exchange rates were not discussed in the research. Another important issue is the impact of the general price level. Constant price data were used in the research. Given the low inflation value, it did not make a difference in comparison to using current value log prices. Using a constant value mitigated the impact of general price changes. However, it will be necessary to recalculate the forecasts during periods of higher inflation. In addition, impacts of changes in the international market and policy are also not dealt with in the research. Incorporating influencing factors into forecasts of log prices should also be a focus of further research.

Supplementary Materials: Supplementary materials are available online at http:/ /www.mdpi.com/1999-4907/ 7/5/94/s1.

Acknowledgments: This research was funded by Forestry and Forest Products Research Institute (FFPRI), a National Research and Development Agency, Japan. The authors thank two anonymous reviewers for their constructive comments.

Author Contributions: Hirofumi Kuboyama, Tetsuya Michinaka, Kazuya Tamura, Hiroyasu Oka and Nobuyuki Yamamoto conceived and designed the study; Kazuya Tamura and Tetsuya Michinaka collected the data; Nobuyuki Yamamoto contributed in literature review; Tetsuya Michinaka analyzed the data and wrote the manuscript; all authors contributed to the revision of the final manuscript.

Conflicts of Interest: The authors declare no conflict of interest.

\section{References}

1. Endo, K. Why Log Prices Collapsed: Reasons, Mechanism and Measures; National Forestry Extension Association: Tokyo, Japan, 2013; p. 144.

2. Mochizuki, R. A statistical study on fluctuations in prices of main forest products. Bull. Tokyo Imp. Univ. For. 1929, 7, 1-121.

3. Mitsui, T. On seasonal movements of timber prices. In Forestry Economic and Policy Materials; The Japan Forestry Association: Tokyo, Japan, 1938; Volume 3, pp. 43-56.

4. Shindo, R. The Future of the Wood Market and Industry; Price Agency: Tokyo, Japan, 1949; p. 221.

5. Akai, H. Research on Trend of Timber Prices; Bulletin of Forestry Management Institute: Tokyo, Japan, 1965; Volume 63, p. 302.

6. Matsumoto, K. Research on Cyclic Fluctuations of Timber Prices; Bulletin of Forestry Management Institute: Tokyo, Japan, 1966; Volume 63, p. 92. 
7. Mori, Y. A Study on the Time-Series-Analysis of Lumber Price in Japan. J. Jpn. For. Soc. 1970, 52, $227-237$.

8. Matsushita, K. Applications of spectral analysis to the cyclical fluctuations of lumber prices. Trans. Jpn. For. Soc. 1984, 95, 17-18.

9. Matsushita, K.; Handa, R. The cyclical fluctuation of lumber price. Bull. Kyoto Univ. For. 1981, 53, 76-86.

10. Yukutake, K. Time series analysis of timber price fluctuation after World War II. The Current State of Japanese Forestry. In Proceedings of the IUFRO World Congress, Kyoto, Japan, 6-17 September 1981; Volume 1, pp. 41-54.

11. Yukutake, K.; Yoshimoto, A.; Higuchi, Y. Time series analysis of timber prices at two private auction markets in Kyushu Japan. Jpn. J. For. Plan. 2004, 38, 61-74.

12. Kuboyama, H.; Tachibana, S. Statistical analysis on price trend of softwood roundwood. Kanto J. For. Res. 2014, 65, 9-12.

13. Elias, R.J.; Montgomery, D.C.; Kulahci, M. An overview of short-term statistical forecasting methods. Int. J. Manag. Sci. Eng. Manag. 2006, 1, 17-36.

14. Makridakis, P.; Wheelwright, S.C.; Hyndman, R.J. Foresting: Methods and Applications, 3rd ed.; Wiley: New York, NY, USA, 1998; p. 656.

15. Hyndman, R.J.; Koehler, A.B.; Ord, J.K.; Synder, R.D. Forecasting with Exponential Smoothing: The State Space Approach; Springer: Berlin, Germany, 2008; p. 359.

16. R Core Team. R: A Language and Environment for Statistical Computing. R Foundation for Statistical Computing, Vienna, Austria. Available online: http:/ /www.R-project.org/ (accessed on 2 February 2015).

17. Hyndman, R.J. Forecasting Functions for Time Series and Linear Models. Available online: http:/ / github.com/robjhyndman/forecast (accessed on 25 October 2015).

18. Forestry Agency. Statistical Handbook of Forest and Forestry; Forestry Agency, Ministry of Agriculture, Forestry and Fisheries: Tokyo, Japan, 2013; p. 262.

19. Forestry Agency. Balance Sheet of Wood. Available online: http://www.rinya.maff.go.jp/j/press/kikaku/ pdf/150929-02.pdf (accessed on 5 December 2015).

20. MAFF. Ministry of Agriculture, Forestry and Fisheries. Available online: http://www.maff.go.jp/j/tokei/ kouhyou/kensaku/bunya5.html (accessed on 15 October 2015).

21. Findley, D.F.; Monsell, B.C.; Bell, W.R.; Otto, M.C.; Chen, B.C. New Capabilities and methods of the X-12-ARIMA seasonal-adjustment Program. J. Bus. Econ. Stat. 1998, 16, 127-152. [CrossRef]

22. Makridakis, S.; Hibon, M. The M3-Competition: Results, conclusions and implications. Int. J. Forecast. 2000, 16, 451-476. [CrossRef]

23. Hyndman, R.J.; Koehler, A.B.; Snyder, R.D.; Grose, S. A state space framework for automatic forecasting using exponential smoothing methods. Int. J. Forecast. 2002, 18, 439-454. [CrossRef]

24. Sanders, D.R.; Manfredo, M.R. USDA livestock price forecasts: A comprehensive evaluation. J. Agric. Resour. Econ. 2003, 28, 316-334.

25. Sanders, D.R.; Manfredo, M.R. Rationality of U.S. Department of Agriculture Livestock price forecasts: A unified approach. J. Agric. Appl. Econ. 2007, 39, 75-85.

26. Gelper, S.; Fried, R.; Croux, C. Robust forecasting with exponential and Holt-Winters smoothing. J. Forecast. 2010, 29, 285-300. [CrossRef]

27. Hassani, H.; Silva, S.S.; Gupta, R.; Segnon, M.K. Forecasting the price of gold. Appl. Econ. 2015, 47, 4141-4152. [CrossRef]

28. Guttormsen, A.G. Forecasting weekly salmon prices: Risk management in fish farming. Aquac. Econ. Manag. 1999, 3, 159-166. [CrossRef]

29. Holt, C.C. Forecasting seasonals and trends by exponentially weighted moving averages (a reprinted version). Int. J. Forecast. 2004, 20, 5-10. [CrossRef]

30. Brown, R.G. Statistical Forecasting for Inventory Control; McGraw/Hill: New York, NY, USA, 1959; p. 223.

31. Winters, P.R. Forecasting Sales by Exponentially Weighted Moving Averages. Manag. Sci. 1960, 6, $324-342$. [CrossRef]

32. Hyndman, R.J.; Athanasopoulos, G. Forecasting: Principles and Practice. Available online: http:/ / otexts.org/fpp/ (accessed on 10 September 2015).

33. Burnham, K.P.; Anderson, D.R. Model Selection and Multimodel Inference: A Practical Information-Theoretic Approach, 2nd ed.; Springer-Verlag: Berlin, Germany, 2002; p. 488.

34. Hamilton, J.D. Time Series Analysis; Princeton University Press: Princeton, NJ, USA, 1994; p. 799. 
35. Harvey, A.C. Forecasting, Structural Time Series and the Kalman Filter; Cambridge University Press: Cambridge, UK, 1989; p. 554.

36. Said, S.E.; Dickey, D.A. Testing for unit roots in autoregressive-Moving Average Models of Unknown Order. Biometrika 1984, 71, 599-607. [CrossRef]

37. Trapletti, A.; Hornik, K.; LeBaron, B. Time Series Analysis and Computational Finance. Package "tseries" in R. Available online: https://cran.r-project.org/web/packages/tseries/tseries.pdf (accessed on 10 December 2015).

38. Ljung, G.; Box, G. On a measure of lack of fit in Time Series Models. Biometrika 1978, 65, 297-303. [CrossRef]

39. Zamani, M. An econometrics forecasting model of short term oil spot price. In Proceedings of the 6th IAEE European Conference, Zurich, Switzerland, 2-3 September 2004.

40. Nogales, F.J.; Contreras, J.; Conejo, A.J.; Espinola, R. Forecasting next-day electricity prices by time series models. IEEE Trans. Power Syst. 2002, 17, 342-348. [CrossRef]

41. Weron, R. Electricity price forecasting: A review of the state-of-the-art with a look into the future. Int. J. Forecast. 2014, 30, 1030-1081. [CrossRef]

(C) 2016 by the authors; licensee MDPI, Basel, Switzerland. This article is an open access article distributed under the terms and conditions of the Creative Commons Attribution (CC-BY) license (http://creativecommons.org/licenses/by/4.0/). 